\title{
Primary Hyperparathyroidism-Related Brown Tumors Mimicking Other Giant Cell-Containing Skeletal Tumors: Role of Correlative Imaging in Diagnosis
}

\author{
Fathima Fijula Palot Manzil ${ }^{1}$, Pradeep Bhambhvani ${ }^{1}$, Surjith Vattoth ${ }^{2}$, Shree Krishna Subedi ${ }^{3}$, Asim Kumar Bag ${ }^{2}$, \\ and Janis P. O’Malley ${ }^{1}$ \\ ${ }^{1}$ Division of Nuclear Medicine, Department of Radiology, University of Alabama at Birmingham, Birmingham, Alabama; \\ ${ }^{2}$ Neuroradiology Section, Department of Radiology, University of Alabama at Birmingham, Birmingham, Alabama; and ${ }^{3}$ Department \\ of Radiology, Medical University of South Carolina, Charleston, South Carolina
}

\begin{abstract}
A patient initially suspected of having a giant cell granuloma was subsequently found-through additional imaging with 99mTc-sestamibi and ultrasound-to have osteolytic brown tumors caused by a parathyroid adenoma. Brown tumors that relate to primary hyperparathyroidism may mimic other skeletal tumors that contain giant cells, presenting difficulty with accurate diagnosis. Correlative imaging can have a valuable role in such cases, potentially avoiding the extensive work-up usually done for suspected bone metastases.
\end{abstract}

Key Words: bone; correlative imaging; endocrinology; brown tumor; giant cell; hyperparathyroidism

J Nucl Med Technol 2013; 41:46-48

DOI: 10.2967/jnmt.112.115204

\section{W}

e present a case of a young woman with an osteolytic femur and maxillary brown tumors from primary hyperparathyroidism who was misdiagnosed as having giant cell-rich tumors including aneurysmal bone cyst and giant cell granuloma. Correlation between biochemical and multimodality imaging findings eventually led to the accurate diagnosis of brown tumors.

\section{CASE REPORT}

A 23-y-old woman presented with a pathologic fracture of the right femoral neck secondary to osteolytic lesions seen on CT (Fig. 1A). The fracture required hip hemiarthroplasty. On pathologic examination, an aneurysmal bone cyst was found to correlate with the CT findings. The patient's work-up included a skeletal survey that was notable for hypercalcemia and multiple osteolytic lesions, several

\footnotetext{
Received Oct. 3, 2012; revision accepted Jan. 14, 2013.

For correspondence or reprints contact: Pradeep Bhambhvani, University of Alabama at Birmingham, 619 19th St. S., JT 261, Birmingham, AL 35249. E-mail: pbhambhvani@uabmc.edu

Published online Feb. 5, 2013.

COPYRIGHT @ 2013 by the Society of Nuclear Medicine and Molecular Imaging, Inc.
}

of which were hot on a whole-body bone scan obtained $3 \mathrm{~h}$ after intravenous injection of $740 \mathrm{MBq}(20 \mathrm{mCi})$ of ${ }^{99 \mathrm{~m} T c}-$ methylene diphosphonate (Fig. 1B). Contrast-enhanced maxillofacial CT (iopamidol [Isovue; Bracco], $85 \mathrm{~mL} ; 120 \mathrm{kVp}$; $160 \mathrm{~mA} ; 180$-mm field of view) was also performed for evaluation of a left mandibular mass and numbness and revealed multiple osteolytic facial lesions (Figs. 2A and 2B). Biopsy of the left mandibular mass was consistent with a giant cell granuloma. Further work-up demonstrated an elevated level of serum parathyroid hormone $(1,492 \mathrm{pg} / \mathrm{mL}$; reference range, $10-90 \mathrm{pg} / \mathrm{mL})$ and calcium $(14.9 \mathrm{mg} / \mathrm{dL}$; reference range, $8.4-10.2 \mathrm{mg} / \mathrm{dL}$ ), consistent with primary hyperparathyroidism. These findings led to additional imaging, including a parathyroid scan with early $(15 \mathrm{~min})$ and delayed $(2 \mathrm{~h})$ planar images obtained after intravenous injection of $740 \mathrm{MBq}(20 \mathrm{mCi})$ of ${ }^{99 \mathrm{~m}} \mathrm{Tc}-$ sestamibi (Fig. 3A) and neck ultrasound (Fig. 3B), both of which showed a left inferior parathyroid adenoma, which was later confirmed on pathologic examination after surgical excision. The right hip, left mandible, and numerous other osteolytic skeletal lesions were thus attributed to primary hyperparathyroidism-related multifocal brown tumors. After left inferior parathyroidectomy, the levels of serum parathyroid hormone $(32 \mathrm{pg} / \mathrm{mL})$ and calcium $(9.3 \mathrm{mg} / \mathrm{dL})$ returned to normal, indicating cure. Follow-up maxillofacial CT revealed regression and sclerosis of the various osteolytic facial lesions (Fig. 2C) after correction of hyperparathyroidism.

\section{DISCUSSION}

Giant cells can be seen in many bone tumors, including giant cell tumors, aneurysmal bone cysts, giant cell granulomas, giant cell-rich osteosarcomas, chondrosarcomas, and brown tumors associated with hyperparathyroidism (1). Because these various tumors resemble one another on imaging and pathology, our patient was erroneously diagnosed initially with an aneurysmal bone cyst involving the right femoral neck and subsequently with a giant cell granuloma of the left mandible. A combination of her clinical presentation, imaging findings, and the biochemical 


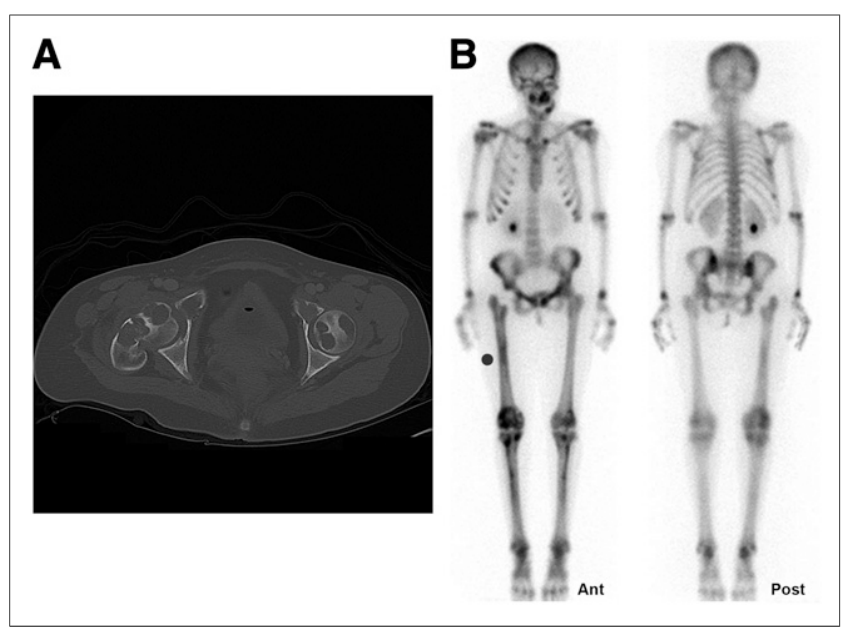

FIGURE 1. (A) Axial CT image of hips (iopamidol, $85 \mathrm{~mL} ; 120$ $\mathrm{kVp} ; 210 \mathrm{~mA}$; 380-mm field of view) shows pathologic fracture of right femoral neck with multiple osteolytic lesions involving femurs bilaterally and bony pelvis. (B) Whole-body bone scan with multifocal lesions involving mandible, maxilla, pelvis, and tibial bones. findings of primary hyperthyroidism related to a parathyroid adenoma led to the accurate diagnosis of multiple skeletal brown tumors. Thus, the extensive work-up usually done for suspected bone metastases $(2,3)$ could be avoided.

Bone disease and renal stone disease are the most common clinical manifestations of primary hyperparathyroidism (4). The bone disease seen in hyperparathyroidism, also referred to as osteitis fibrosa cystica, is rare today, occurring mostly in cases of severe disease and clinically presenting as bone pain. Imaging findings may include osteopenia, multiple osteolytic lesions from brown tumors, bone cysts, a salt-and-pepper appearance of the skull, and the characteristic radiographic findings of erosions and subperiosteal bone resorption most commonly involving the radial aspect of the middle phalanges of the index and middle fingers (5).

Brown "tumors" of hyperparathyroidism are not actual tumors but result from excessive osteoclast activity. They consist of multinucleated osteoclasts (giant cells) and spindle-

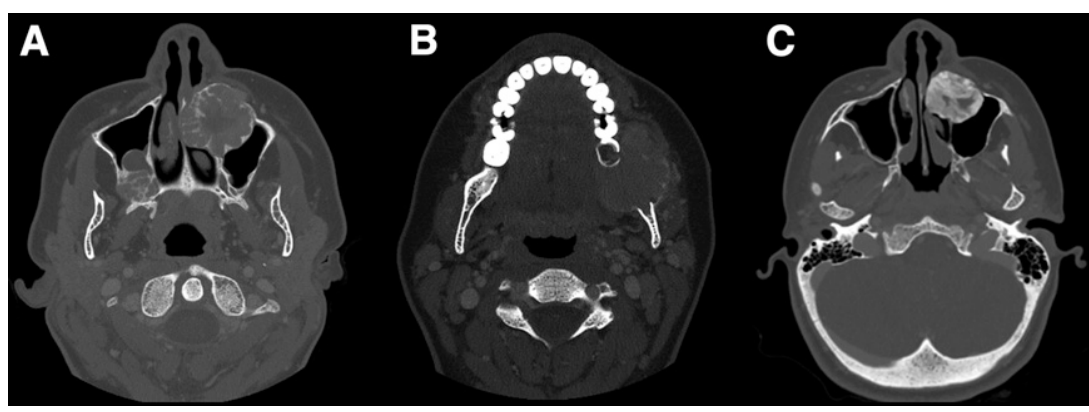

FIGURE 2. (A and B) Axial maxillofacial CT images reveal expansile osteolytic lesions involving right and left maxilla and left mandible. (C) Axial maxillofacial CT image demonstrates interval sclerosis and regression of left maxillary lesion after parathyroidectomy.
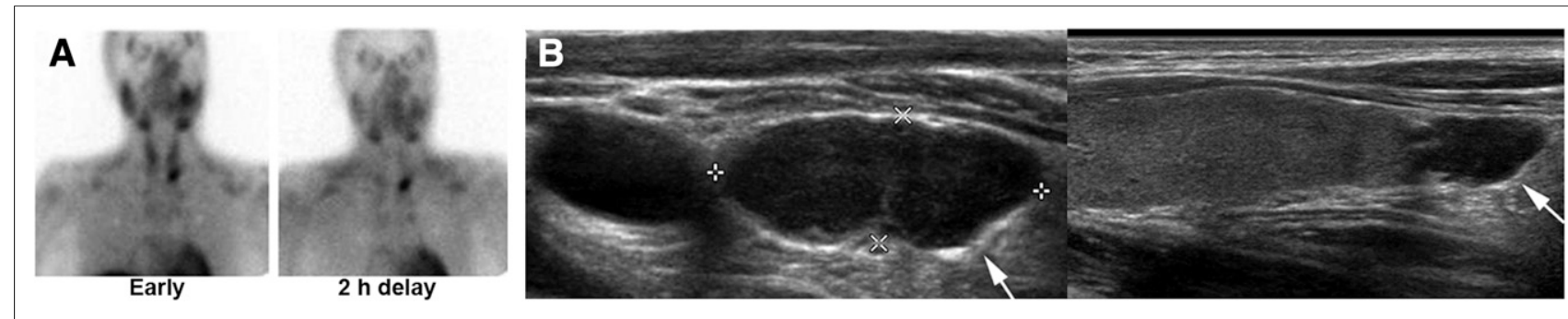

FIGURE 3. Planar ${ }^{99 m T c-s e s t a m i b i ~ s c a n ~(A) ~ a n d ~ u l t r a s o u n d ~(B) ~ d e p i c t ~ l a r g e ~ l e f t ~ i n f e r i o r ~ p a r a t h y r o i d ~ a d e n o m a ~(a r r o w s) . ~}$

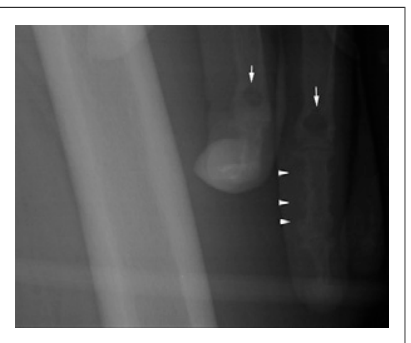

FIGURE 4. Frontal radiograph of left femur that incidentally included left hand depicts erosions and subperiosteal bone resorption on radial aspect of mid phalanx of middle finger (arrowheads) and brown tumors in proximal phalanges (arrows). shaped stromal cells in a background of fibrous matrix and poorly mineralized woven bone. Their brown color is due to hemosiderin deposition. These tumors are known to regress after correction of hyperparathyroidism. Pathologic differentiation of brown tumors from other giant cell-containing bone lesions can be challenging (6). In addition to multiple osteolytic brown tumors, our patient also had the characteristic radiographic findings of hyperparathyroidism, including erosions and subperiosteal bone resorption on the radial aspect of the mid phalanx of the left middle 
finger, the latter incidentally seen in her initial radiograph (Fig. 4).

\section{CONCLUSION}

This case study is evidence of the value of ${ }^{99 m} \mathrm{Tc}-$ sestamibi scanning and ultrasound in the accurate presurgical localization of the culprit parathyroid adenoma causing multiple osteolytic brown tumors, thus avoiding the extensive work-up usually done for suspected bone metastases.

\section{DISCLOSURE}

No potential conflict of interest relevant to this article was reported.

\section{REFERENCES}

1. Werner M. Giant cell tumor of bone: morphological, biological and histogenetical aspects. Int Orthop. 2006;30:484-489.

2. Hoshi M, Takami M, Kajikawa M, et al. A case of multiple skeletal lesions of brown tumors, mimicking carcinoma metastases. Arch Orthop Trauma Surg. 2008; 128:149-154.

3. Joyce JM, Idea RJ, Grossman SJ, Liss RG, Lyons JB. Multiple brown tumors in unsuspected primary hyperparathyroidism mimicking metastatic disease on radiograph and bone scan. Clin Nucl Med. 1994;19:630-635.

4. Silverberg SJ, Bilezikian JP. Evaluation and management of primary hyperparathyroidism. J Clin Endocrinol Metab. 1996;81:2036-2040.

5. Genant HK, Hick LL, Lanzl LH, Rossmann K, Horst JV, Paloyan E. Primary hyperparathyroidism: a comprehensive study of clinical, biochemical, and radiographic manifestations. Radiology. 1973;109:513-524.

6. Jain M, Aiyer HM, Singh M, Narula M. Fine-needle aspiration diagnosis of giant cell tumour of bone presenting at unusual sites. Diagn Cytopathol. 2002;27:375378. 